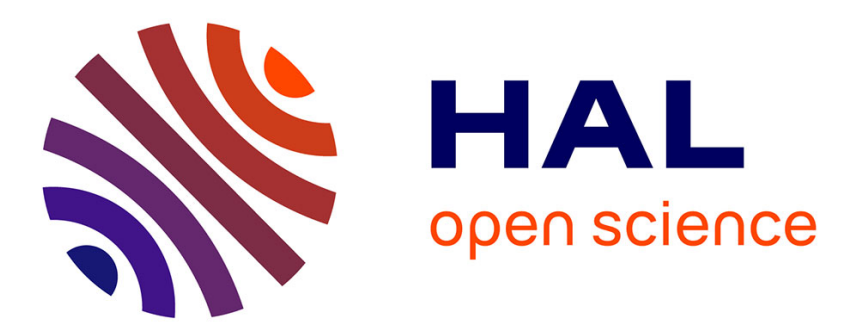

\title{
Endoplasmic reticulum generates calcium signalling microdomains around the nucleus and spindle in syncytial Drosophila embryos
}

\author{
H. Parry, A. Mcdougall, M. Whitaker
}

\section{- To cite this version:}

H. Parry, A. Mcdougall, M. Whitaker. Endoplasmic reticulum generates calcium signalling microdomains around the nucleus and spindle in syncytial Drosophila embryos. Biochemical Society Transactions, 2006, 34 (3), pp.385-388. 10.1042/BST0340385 . hal-03025952

\section{HAL Id: hal-03025952 \\ https://hal.science/hal-03025952}

Submitted on 16 Dec 2020

HAL is a multi-disciplinary open access archive for the deposit and dissemination of scientific research documents, whether they are published or not. The documents may come from teaching and research institutions in France or abroad, or from public or private research centers.
L'archive ouverte pluridisciplinaire HAL, est destinée au dépôt et à la diffusion de documents scientifiques de niveau recherche, publiés ou non, émanant des établissements d'enseignement et de recherche français ou étrangers, des laboratoires publics ou privés. 


\title{
Endoplasmic reticulum generates calcium signalling microdomains around the nucleus and spindle in syncytial Drosophila embryos
}

\author{
H. Parry, A. McDougall and M. Whitaker ${ }^{\mathbf{1}}$ \\ Institute for Cell and Molecular Biosciences, Medical School, University of Newcastle upon Tyne, Newcastle upon Tyne NE2 4HH, U.K.
}

\begin{abstract}
Cell cycle calcium signals are generated by inositol trisphosphate-mediated release of calcium from internal stores [Ciapa, Pesando, Wilding and Whitaker (1994) Nature (London) 368, 875-878; Groigno and Whitaker (1998) Cell 92, 193-204]. The major internal calcium store is the ER (endoplasmic reticulum): the spatial organization of the ER during mitosis is important in defining a microdomain around the nucleus and mitotic spindle in early Drosophila embryos [Parry, McDougall and Whitaker (2005) J. Cell Biol. 171, 47-59]. Nuclear divisions in syncytial Drosophila embryos are accompanied by both cortical and nuclear localized calcium transients. Mitosis is prevented by the Ins $P_{3}$ antagonists Xestospongin $C$ and heparin. Nuclear-localized transients and cortical transients rely on extraembryonic calcium, suggesting that ER calcium levels are maintained by calcium influx.
\end{abstract}

\section{Introduction}

Calcium signals control the cell division cycle of early sea urchin [1-3], frog [4-6] and mammalian embryos [7,8]. There is evidence that blocking calcium signals prevents mitosis, but often mitotic calcium signals are small or undetectable [3,7,9-11].

In early syncytial nuclear divisions of Drosophila melanogaster embryos, ER (endoplasmic reticulum) is highly concentrated around the nucleus at prophase and is also associated with the spindle poles [12]. This configuration of ER creates a calcium signalling microdomain [13].

\section{ER separates a calcium signalling microdomain around the nucleus from a cortical calcium domain}

Early Drosophila development involves rapid nuclear divisions that occur in the same cytoplasm [14,15]. Dividing nuclei are first located deep within the embryo and migrate to the embryo cortex during cycles 8 and 9. In later cycles, the nuclei divide just beneath the surface of the embryo, making them amenable to confocal imaging. Co-labelling of microtubules and ER during mitosis shows that the mitotic spindle forms in an environment bounded by ER (Figure 1A), with ER particularly prominent at the spindle poles. $[\mathrm{Ca}]_{\mathrm{i}}$ (intracellular free calcium concentration) varies markedly in the embryo during successive nuclear cycles (see Supplementary Video 1 at http://www.biochemsoctrans.org/bst/034/ bst0340385add.htm). Highest levels of cortical $[\mathrm{Ca}]_{\mathrm{i}}$ occur during interphase [13]. Nonetheless, even in interphase, ER

Key words: calcium signalling microdomain, cortex, Drosophila embryo, endoplasmic reticulum, extraembryonic calcium, mitosis.

Abbreviations used: BAPTA, bis-(o-aminophenoxy)ethane- $N, N, N^{\prime}, N^{\prime}$-tetra-acetic acid; CaGr, Calcium Green Dextran; [Ca $]_{i}$, intracellular free calcium concentration; ER, endoplasmic reticulum. ${ }^{1}$ To whom correspondence should be addressed (email michael.whitaker@ncl.ac.uk). surrounds the nucleus and forms a privileged calcium environment in which calcium concentrations are lower in the nucleus than in the cortex [13]. Figure 1(B) shows simultaneous measurement of calcium and ER in the cortex of a syncytial embryo at the time of prophase and illustrates how the disposition of ER generates two calcium signalling domains within the cortical bud. As nuclei proceed through mitosis and chromosomes separate, the relation between ER and the spindle becomes quite complex, with invasion by ER of the spindle mid-zone and accretion around the separating chromosomes (Figure 1C).

\section{Calcium release at mitosis in the nuclear microdomain requires both Ins $P_{3}$ and extracellular calcium}

Cell cycle calcium signals are triggered by $\operatorname{Ins} P_{3}[1,2,6]$. Drosophila embryos express an Ins $P_{3}$ receptor [16,17]. Heparin and Xestospongin $\mathrm{C}$ are agents that inhibit the interaction of $\operatorname{Ins} P_{3}$ with the Ins $P_{3}$ receptor [18,19]. Figure 2(A) shows that interfering with Ins $P_{3}$ signalling using either Xestospongin $\mathrm{C}$ [20] or heparin [1] as antagonists prevents the completion of nuclear division by interfering with chromatid disjunction, as visualized using histone-tagged chromatin. Complete arrest occurs over three nuclear cycles at a concentration of approx. $125 \mu \mathrm{g} / \mathrm{ml}$ heparin.

We investigated the requirement for extraembryonic calcium during the syncytial nuclear divisions. In Drosophila embryos, extracellular fluid is contained in the perivitelline space outside the plasma membrane, bounded by the vitelline membrane. We titrated the calcium concentration in the perivitelline space using dibromoBAPTA [where BAPTA is bis-(o-aminophenoxy)ethane- $N, N, N^{\prime}, N^{\prime}$-tetra-acetic acid]. Microinjection of dibromoBAPTA to a final concentration of $10 \mathrm{mM}$ caused a fall in calcium levels to micromolar levels, 
Figure 1 | ER-bounded domains in syncytial Drosophila embryos

(A) Co-labelling of microtubules using fluorescein-tubulin and ER using DilC $C_{18}$ (1,1'-dioctadecyl 3,3,3',3'-tetramethylindocarbocyanine perchlorate). A ring of ER surrounds the spindle during mitosis. NEB, nuclear envelope breakdown. (B) Simultaneous imaging of [Ca $]_{i}$ and ER in cortical buds during interphase. Calcium concentrations appear to be lower in the nuclei and ER is interposed between regions of high cortical calcium concentration and the lower calcium levels in the nuclei. (C) Distribution of ER as the nuclei move through metaphase into interphase. At metaphase (0 min), ER surrounds the spindle and is concentrated at the spindle poles (see $\mathbf{A}$ above). At anaphase (1 min), this distribution persists as the spindle elongates. At telophase (2 min), ER invades the spindle mid-zone and surrounds the chromosomes. In early interphase (3 min), ER becomes organized around the nuclei more dispersely. Confocal sections are shown. For methods, see [13]. Images are still frames taken from Supplementary Video 2 that can be seen at http://www.biochemsoctrans.org/bst/ 034/bst0340385add.htm.

A

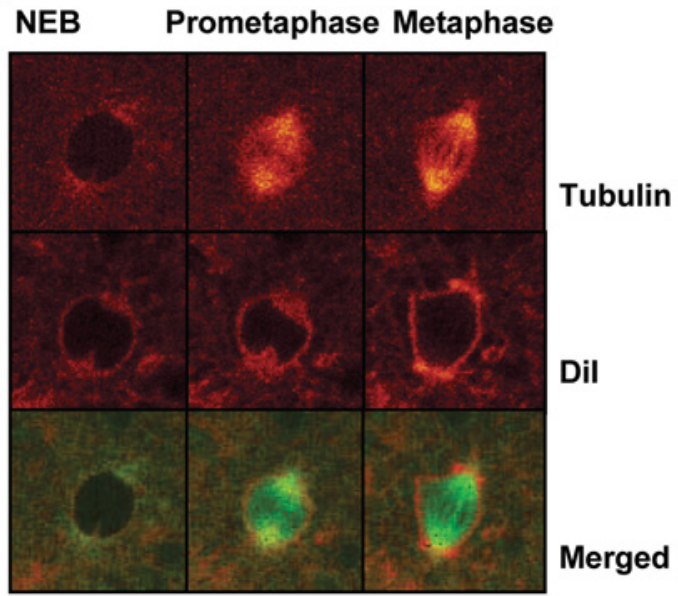

B

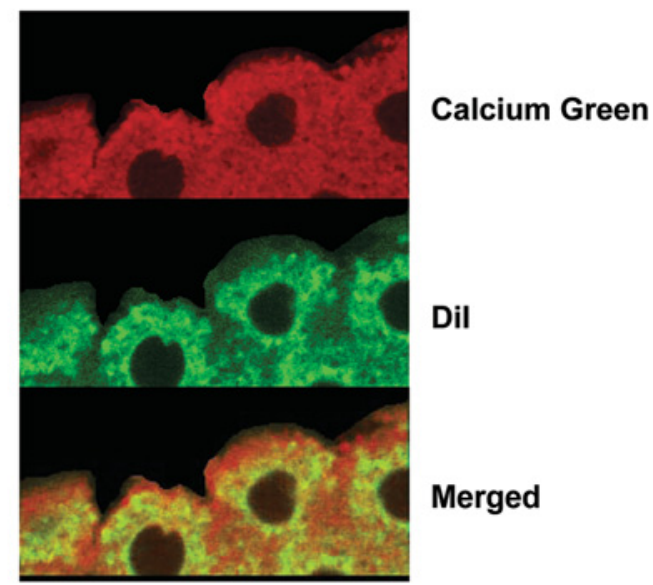

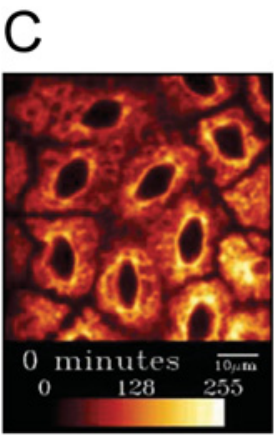
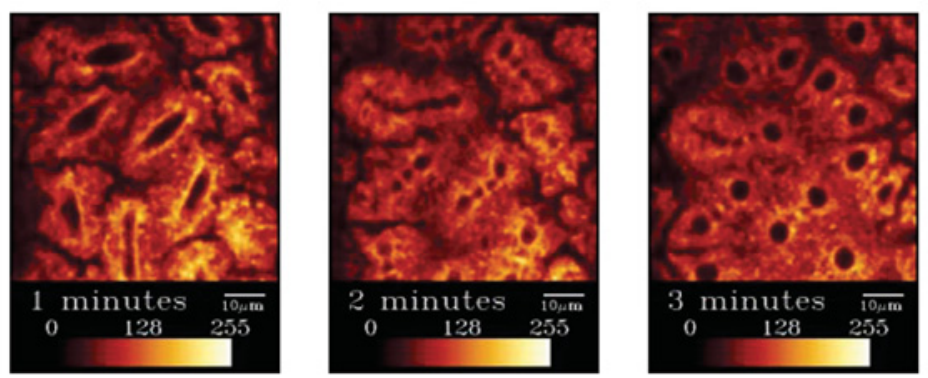

as judged by the fall in the signal from the calcium indicator $\mathrm{CaGr}$ (Calcium Green Dextran) (Figure 2B, i). Microinjection of dibromoBAPTA to a concentration of $5 \mathrm{mM}$ did not alter the $\mathrm{CaGr}$ signal (Figure 2B, ii), demonstrating that the calcium concentration in the perivitelline space was greater than $5 \mathrm{mM}$, but less than $10 \mathrm{mM}$. We found that injection of $5 \mathrm{mM}$ dibromoBAPTA into the perivitelline space did not affect the nuclear division cycle, but that reducing perivitelline calcium concentrations to micromolar levels with $10 \mathrm{mM}$ dibromoBAPTA led to cell cycle arrest (Figure 2B, iii).

\section{Discussion}

The syncytial nuclear divisions of early Drosophila embryos are well suited to investigation of the role of calcium in mitosis because ER does not invade the nucleus, instead surrounding the nucleus and mitotic spindle [12]. This disposition of ER defines spatially identifiable domains in which we have shown that calcium concentrations are differentially regulated. While calcium signalling microdomains have never previously been identified during mitosis, there are reports that calcium signals during mitosis are confined to the mitotic spindle pole $[21,22]$. The principle that calcium signalling subdomains can exist within a single cell bounded by ER has been well established in pancreatic acinar cells [23].

Here, we show that ER separates two calcium signalling domains within the cortical buds of syncytial Drosophila embryos. The dominant and striking calcium signal in these embryos is cortical and is associated with actin cytoskeletal rearrangements [13]. High $[\mathrm{Ca}]_{\mathrm{i}}$ correlates with the phase of cortical contraction associated with interphase nuclei [14] and inhibited by cytochalasins [24]. The ER forms a 
Figure 2 Block of nuclear division by inhibition of Ins $P_{3}$ signalling and by removal of extracellular calcium

(A) In separate experiments, spindles and chromosomes were tagged with fluorescein-labelled tubulin or fluorescein-labelled histones. (i) Control to show normal progress through mitosis, with a doubling of nuclei. (ii, iii) The Ins $P_{3}$ antagonist Xestospongin ( prevents anaphase onset: metaphase spindles form normally, but chromosomes fail to segregate at anaphase. (iv, v) Heparin leads to a similar outcome as in (ii) and (iii); the arrow in (v) identifies a single nucleus for clarity. (vi) Inhibition of mitosis by Xestospongin C is progressive, with 75\% of nuclei arrested after one cell cycle and the remainder in the next cell cycle. (vii) Dose-response curve for heparin. (B) The perivitelline space was first labelled by injection of CaGr. The calcium chelator dibromoBAPTA was then injected to a final concentration of (i) $10 \mathrm{~mm}$ or (ii) $5 \mathrm{mM}$. DibromoBAPTA (10 mM) markedly reduced the CaGr signal, indicating that the chelator reduced the calcium concentration of the perivitelline space to micromolar levels, while $5 \mathrm{mM}$ dibromoBAPTA was unable to effect this. These results indicate that the calcium concentration in the perivitelline space is between 5 and $10 \mathrm{~mm}$. (iii) The nuclear division cycle is fully disrupted by reducing extracellular calcium to micromolar levels. For methods see [13].

A

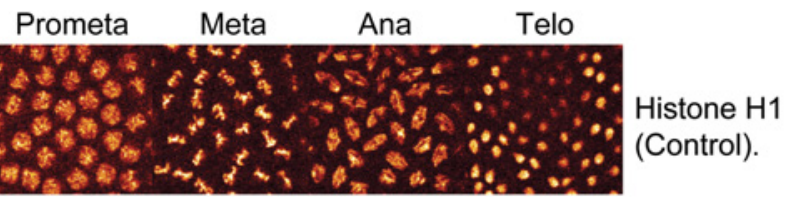

ii.

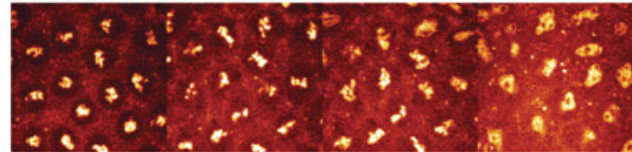

iii.

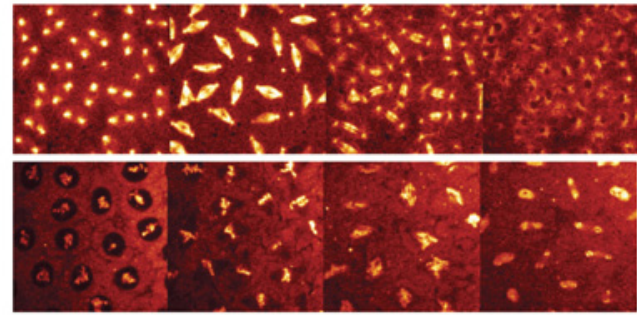

V.

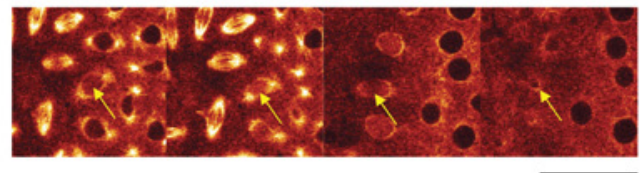

(vi).

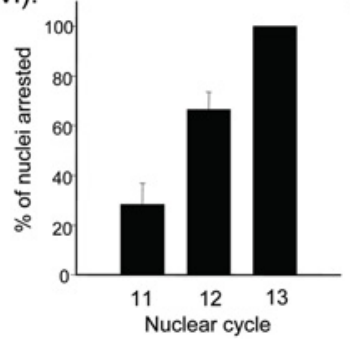

(vii).

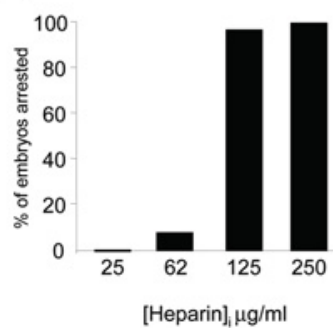

Tubulin +

Heparin

B (i)

DibromoBAPTA injection

Histone $\mathrm{H} 1+$

Xestospongin

Tubulin +

Xestospongin

Histone $\mathrm{H} 1$ +

Heparin

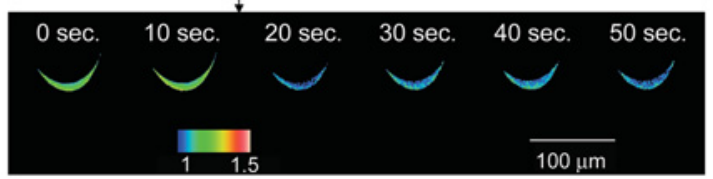

(ii) DibromoBAPTA injection

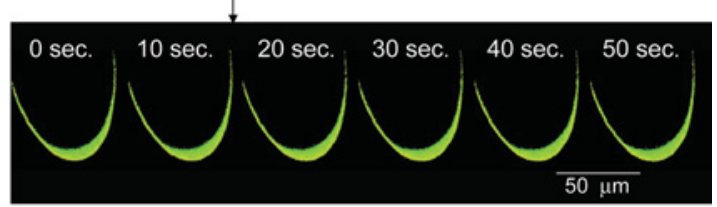

(iii)

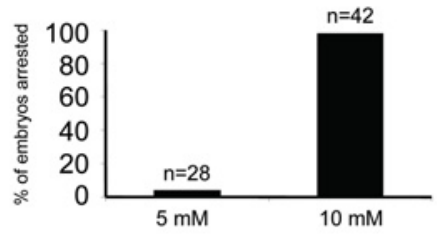

barrier between the cortex and the nucleus. During episodes of high cortical $[\mathrm{Ca}]_{\mathrm{i}}$, it preserves a lower calcium concentration within the nucleus; at a time when cortical $[\mathrm{Ca}]_{\mathrm{i}}$ is low, the ER generates a calcium signal within the spindle that triggers anaphase [13].

These observations in Drosophila embryos demonstrate that calcium concentrations in the nucleus and spindle are controlled independently of bulk cytoplasmic calcium concentrations. It is known that in most cell types, ER associates intimately with the nucleus and spindle [25]. This has been interpreted as a mechanism to ensure proportionate inheri- tance of ER when cells divide [26]. The intimate association of ER with the nucleus and spindle suggests that similar calcium signalling microdomains are present during mitosis in other cell types. However, the close intermingling of ER and spindle microtubules in most cell types may make very local calcium signals within the dividing nucleus more difficult to resolve and explain why such signals are not always readily detectable $[3,7,9-11]$.

We also show here that the $\operatorname{Ins} P_{3}$-dependent calcium signals that control entry into and exit from mitosis in syncytial Drosophila embryos are dependent on extraembryonic 
calcium. Calcium from the perivitelline space is essential to maintain the nuclear division cycles. It will be interesting to determine whether calcium from the extracellular space can tunnel through ER directly to the mitotic apparatus, as had been shown to occur in the apical pole of pancreatic acinar cells $[27,28]$.

This work was supported by grants from the Wellcome Trust and the Biotechnology and Biological Sciences Research Council. We thank Michael Aitchison for help in preparing the Figures.

\section{References}

1 Groigno, L. and Whitaker, M. (1998) Cell 92, 193-204

2 Ciapa, B., Pesando, D., Wilding, M. and Whitaker, M., (1994) Nature (London) 368, 875-878

3 Wilding, M., Wright, E.M., Patel, R., Ellis-Davies, G. and Whitaker, M. (1996) J. Cell Biol. 135, 191-199

4 Snow, P. and Nuccitelli, R. (1993) J. Cell Biol. 122, 387-394

5 Miller, A.L., Fluck, R.A., McLaughin, J.A. and Jaffe, L.F. (1993) J. Cell Sci. 106, 523-534

6 Muto, A., Kume, S., Inoue, T., Okano, H. and Mikoshiba, K. (1996)

J. Cell Biol. 135, 181-190

7 Tombes, R.M., Simerly, C., Borisy, G.G. and Schatten, G. (1992)

J. Cell Biol. 117, 799-811

8 Nixon, V.L., Levasseur, M., McDougall, A. and Jones, K.T. (2002) Curr. Biol. 12, 746-750

9 Tombes, R.M. and Borisy, G.G. (1989) J. Cell Biol. 109, 627-636
10 Kao, J.P., Alderton, J., Tsien, R.Y. and Steinhardt, R.A. (1990) J. Cell Biol. 111, 183-196

11 Whitaker, M. and Larman, M.G. (2001) Semin. Cell Dev. Biol. 12, 53-58

12 Bobinnec, Y., Marcaillou, C., Morin, X. and Debec, A. (2003) Cell Motil. Cytoskeleton 54, 217-225

13 Parry, H.D., McDougall, A.D. and Whitaker, M. (2005) J. Cell Biol. 171 47-59

14 Foe, V.E., Odell, G.M. and Edgar, B.A. (1993) in The Development of Drosophilo melonogaster (Bate, M, and Martinez Arias, A., eds.), pp. 149-300, Cold Spring Harbor Laboratory Press, Plainview

15 Foe, V.E. and Alberts, B.M. (1983) J. Cell Sci. 61, 31-70

16 Hasan, G. and Rosbash, M. (1992) Development 116, 967-975

17 Yoshikawa, S., Tanimura, T., Miyawaki, A., Nakamura, M., Yuzaki, M. Furuichi, T. and Mikoshiba, K. (1992) J. Biol. Chem. 267, 16613-16619

18 Gafni, J., Munsch, J.A., Lam, T.H., Catlin, M.C., Costa, L.G., Molinski, T.F. and Pessah, I.N. (1997) Neuron 19, 723-733

19 Ghosh, T.K., Eis, P.S., Mullaney, J.M., Ebert, C.L. and Gill, D.L. (1988) J. Biol. Chem. 263, 11075-11079

$20 \mathrm{Hu}$, Q., Deshpande, S., Irani, K. and Ziegelstein, R.C. (1999) J. Biol. Chem. 274, 33995-33998

21 Keith, C.H., Ratan, R., Maxfield, F.R., Bajer, A. and Shelanski, M.L. (1985) Nature (London) 316, 848-850

22 Ratan, R.R., Shelanski, M.L. and Maxfield, F.R. (1986) Proc. Natl. Acad. Sci. U.S.A. 83, 5136-5140

23 Ashby, M.C. and Tepikin, A.V. (2002) Physiol. Rev. 82, 701-734

24 Hatanaka, K. and Odada, M. (1991) Development 111, 909-920

25 Terasaki, M. and Jaffe, L.A. (1991) J. Cell Biol. 114, 929-940

26 Barr, F.A. (2002) Curr. Opin. Cell Biol. 14, 496-499

27 Mogami, H., Nakano, K., Tepikin, A.V. and Petersen, O.H. (1997) Cell 88 , 49-55

28 Gerasimenko, O.V., Gerasimenko, J.V., Rizzuto, R.R., Treiman, M., Tepikin, A.V. and Petersen, 0.H. (2002) Cell Calcium 32, 261-268

Received 5 January 2006 